Western North American Naturalist 68(2), (C) 2008, pp. 161-172

\title{
HYBRIDIZATION BETWEEN A RARE AND INTRODUCED OENOTHERA ALONG THE NORTH PACIFIC COAST
}

\author{
Matthew L. Carlson ${ }^{1}$ and Robert J. Meinke 2
}

\begin{abstract}
Interspecific hybridization has increasingly become regarded as a serious threat to the genetic integrity and persistence of rare plants. Oenothera glazioviana (Onagraceae) is a horticultural species that has escaped cultivation and now threatens the narrow Pacific coastal endemic $O$. wolfii with hybridization. Reports of morphologically intermediate and ecologically aggressive forms prompted this investigation into the extent of hybridization over the range of $O$. wolfii. In particular, this study identifies populations of pure and hybrid origins. We used multivariate methods to characterize the morphological variation of Oregon and northern California coastal Oenothera populations. Putatively pure O. wolfii and O. glazioviana individuals do not overlap in many floral characteristics. We found morphologies ranging between the 2 species in northern California populations, however, supporting the inference of hybridization. Remote O. wolfii populations in Oregon were smaller in almost all characters, and discriminant analysis was able to distinguish the rare species from both hybrids and O. glazioviana. However, 5 of $10 \mathrm{O}$. wolfii populations overlapped significantly with hybrid populations for individual traits and composite morphology, and trait values outside the range of $O$. wolfii were discovered in 2 populations previously considered to be pure. We also discuss the morphological evidence in light of these species' chromosomal complexes and environmental factors.
\end{abstract}

Key words: hybridization, introgression, Oenothera, conservation, rare plants, permanent translocation heterozygotes, morphometric analysis.

Understanding the processes and potential impacts of hybridization becomes more important as related allopatric species are brought into contact by anthropogenic dispersal with increasing frequency (Ellstrand and Elam 1993, Albert et al. 1997, Abbott and Lowe 2004, Prentis et al. 2007). Many cases of hybridization between native and introduced or between rare and common plants have been reported (Rogers et al. 1982, Brochmann 1984, Freas and Murphy 1988, McGranahan et al. 1988, Liston et al. 1990, Reiseberg 1991, Stace 1991, Ellstrand 1992, Levin et al. 1996, Rhymer and Simberloff 1996, Daehler and Strong 1997, Imper 1997, Vilà et al. 2000, Gisler 2003, Malik et al. 2006), some with dramatic effects on the success of the introduced species (Thompson 1991, cf. Prentis et al. 2007). Often hybridization results in more aggressive and successful genotypes (Heiser 1965, Thompson 1991, Ellstrand and Schierenbeck 2000, Whitney et al. 2006), and models indicate that hybridization can dramatically hasten extinction of native species (Wolf et al. 2001, and see Prentis et al. 2007). The addition of new genes via hybridization can also threaten the genetic integrity of native species (Ellstrand 1992, Albert et al. 1997, Wolf et al. 2001) and affect local environmental and genetic adaptation, especially in narrowly distributed species of unique habitats.

Along the southern Oregon and northern California Pacific Coast, an escaped introduced ornamental, Oenothera glazioviana Micheli. ex Mart., is apparently hybridizing with the rare, native species, $O$. wolfii [Munz] Raven, W. Dietr. \& Stubbe. While O. wolfii is threatened by habitat loss and alteration due to coastal development, roadside maintenance activities, and recreation activities (Skinner and Pavlik 1994), the most serious threat is hybridization with O. glazioviana (Dietrich et al. 1997, Gisler and Meinke 1997, Imper 1997).

The habitats of these 2 species are generally dissimilar. Oenothera glazioviana occurs in weed-lots, garden disposal sites, and occasionally along roadsides, while $O$. wolfii prefers natural coastal bluffs and upper beaches. In northern California, however, considerable development up to the beach strand has brought garden-grown $O$. glazioviana in contact with O. wolfii. Although hybrids appear to have greater ecological amplitude than either parent,

\footnotetext{
${ }^{1}$ Alaska Natural Heritage Program, Environment and Natural Resources Institute, University of Alaska-Anchorage, 707 A Street, Anchorage, AK 99503. E-mail: afmlc2@uaa.alaska.edu
}

${ }^{2}$ Department of Botany and Plant Pathology, Oregon State University, Corvallis, OR 97331-2902. 
they nevertheless tend to occupy more disturbed areas, such as imported substrates along roadsides (Dietrich et al. 1997, Imper 1997).

The hybrids are fertile (Carlson and Wierck unpublished data) and capable of very rapid expansion. Hybrids appear to be expanding rapidly along a coastal highway corridor between Eureka, California, and Oregon, in most cases adjacent to current or historic pure $O$. wolfii populations. At 1 site the population size of hybrids jumped from 100 to 7000 in 2 years (Imper 1997). The northernmost populations of $O$. wolfii are relatively remote and buffered by natural habitats; these populations are thought to be free from the immediate threat of hybridization, but O. glazioviana has been observed in anthropogenic habitats on the central Oregon coast, completely overlapping the rare species' range.

The objective of this study was to characterize the morphological variation of individuals and populations relative to putatively pure $O$. wolfii and thus estimate the extent of the hybridization in O. wolfii. Specifically, we asked if the morphological variation in coastal Oenothera plants is consistent with widespread hybridization and introgression (i.e., a high frequency of individuals that are variable and intermediate between parental species). Additionally, using a morphological analysis, we asked which populations appear to have hybrid, introgressed, or a mixture of individuals from the parental species. It is hoped that these methods will be combined with molecular analysis and that the results will aid conservation and recovery efforts in maintaining $O$. wolfii populations and limiting negative impacts of the invasive $O$. glazioviana.

\section{Methods}

\section{Study Species}

Oenothera wolfii is a showy biennial to short-lived perennial, forming large populations in modestly disturbed upper beach sites; however, populations are few and isolated. The species ranges from 50 to $200 \mathrm{~cm}$ tall. Flowers are generally less than $4.0 \mathrm{~cm}$ in diameter $(2.8-4.8 \mathrm{~cm})$, with separate yellow to pale yellow petals and stigmas generally below the anthers. Stems, sepals, and capsules are typically red-tinged and moderately pubescent, frequently with glandular hairs (for a complete description see Dietrich et al. 1997).
Oenothera glazioviana is a very large-flowered biennial, often growing over $150 \mathrm{~cm}$ in height. Normally restricted to gardens, it occasionally establishes outside developed areas. Flowers are $\geq 6.0 \mathrm{~cm}$ in diameter, deep yellow-colored petals overlap broadly, and the stigma is strongly exerted. This species originated in Europe by hybridization between cultivated or naturalized North American species (Cleland 1972, Raven et al. 1979, Wagner 1993). The pistillate parent is suggested to be $O$. biennis or $O$. grandiflora and the staminant parent is likely O. elata (O. hookeri), a species cultivated in European gardens for many years (Raven et al. 1979). The stabilized hybrid was traded as an ornamental by the 1860s and appears to have been transported around the world quickly, as its species description was published in 1882 from Brazilian type specimens (Raven et al. 1979).

Both species are permanent translocation heterozygotes (Dietrich et al. 1997), a cytological condition that influences patterns of fertility and morphological variation (Holsinger and Ellstrand 1984). This system is characterized by extreme genetic linkage. In O. wolfii all 14 chromosomes form a single ring in meiosis, and a ring of 12 and a bivalent occur in $O$. glazioviana (Cleland 1972, Dietrich et al. 1997). Oenothera wolfii has an AA genomic and a plastome I constitution (Wasmund and Stubbe 1986, Dietrich et al. 1997). Both A complexes produce nearly identical phenotypes. Oenothera glazioviana has an $\mathrm{AB}$ genomic and plastome III constitution (Stubbe 1964) and is the only outcrossing permanent translocation heterozygote in the Onagraceae (Raven 1979). For a more complete discussion of permanent translocation heterozygosity, see Cleland (1972), Holsinger and Ellstrand (1984), Chiu and Sears (1993), and Deitrich et al. (1997).

Because genetic recombination is stifled, populations of permanent translocation heterozygotes are highly uniform genetically and have been considered microspecies, resulting in considerable taxonomic confusion (see Dietrich et al. 1997). Theoretically there is little within-population variation, but high amongpopulation variation as genomic complexes become fixed in populations (Holsinger and Ellstrand 1984). Hybridization introduces new genomic complexes that may result in the reduction and eventual loss of the former complex, in addition to disruption of nuclear 


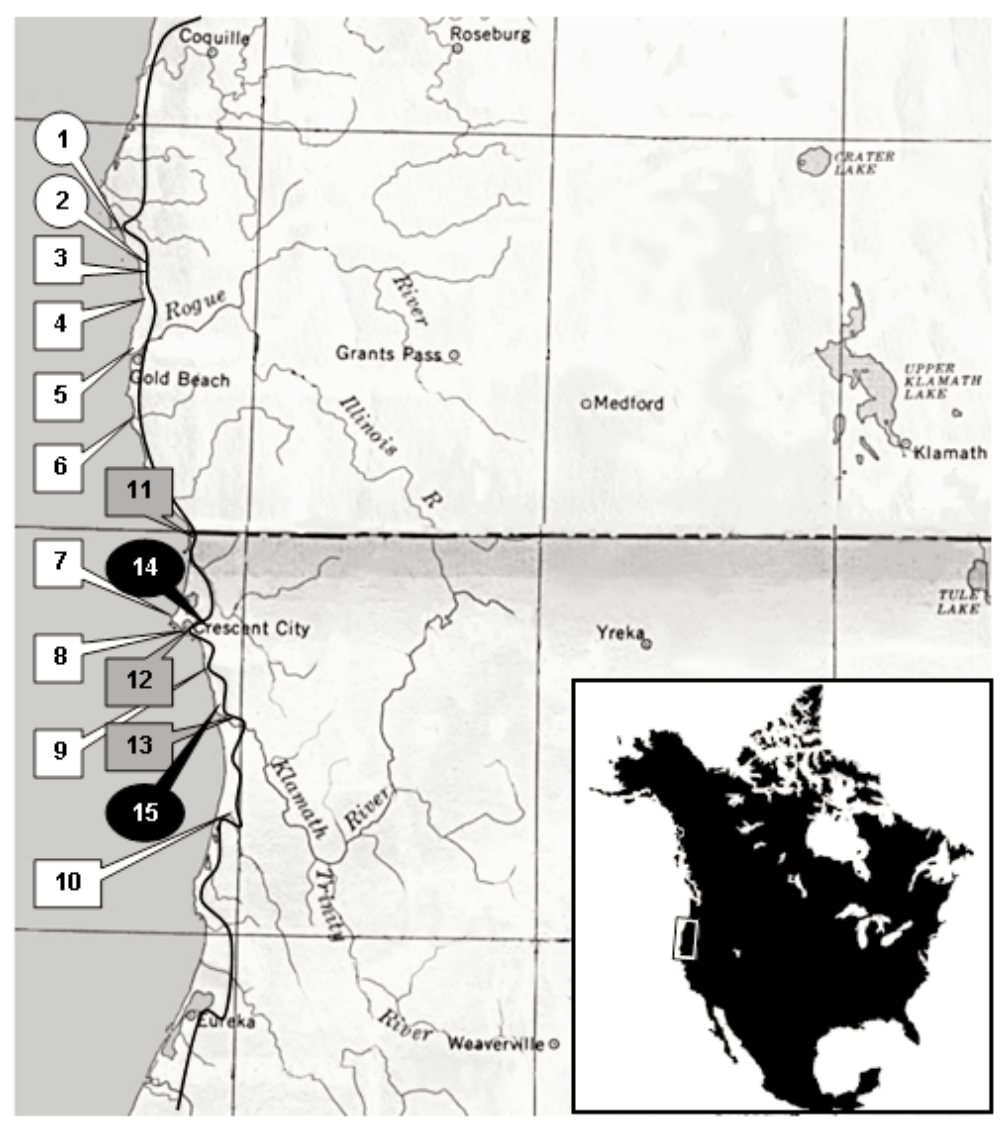

Fig. 1. Locations of study populations along the southern Oregon and northern California coast. Pure O. wolfii populations are indicated with white circles, suspected $O$. wolfii populations are shown as white squares, suspected hybrid populations are shown as gray squares, and pure O. glazioviana are shown as black ellipses. Highway 101 is also shown.

and nuclear-plastid genetic interactions (cf. Chiu and Sears 1993).

\section{Study Area}

To describe morphological variation in these coastal Oenotheras, we sampled 6 of 7 O. wolfii populations in Oregon ( 1 site could not be located). The 2 northern populations are believed to be pure, and the remaining populations are from roadsides or disturbed areas, but are considered to lack contact with $O$. glazioviana. We sampled 4 Californian O. wolfii populations, most of which are assumed to be at higher risk of hybridization (Imper 1997). Sampling of pure $O$. glazioviana was restricted to 2 sites in northern California, as no other accessible populations were observed in the area. Finally, we sampled individuals from 3 previously identified putative hybrid populations (Gisler and Meinke 1997, Imper 1997). Loca- tions of study sites and putative populationlevel identifications are shown in Figure 1.

\section{Sample Collection}

We collected data from all plants in populations with fewer than 15 individuals. In larger populations we conducted a random walk to collect data from approximately 15 individuals located at least $10 \mathrm{~m}$ apart. A single freshly opened flower per plant was chosen for measurements. Normally, only a single flower per plant is open at any one time. On very large plants with multiple open flowers, a single flower was randomly chosen to measure.

\section{Measurements}

We measured a total of 13 quantitative characters in the field on live individuals: flower diameter, mean petal length (averaged 


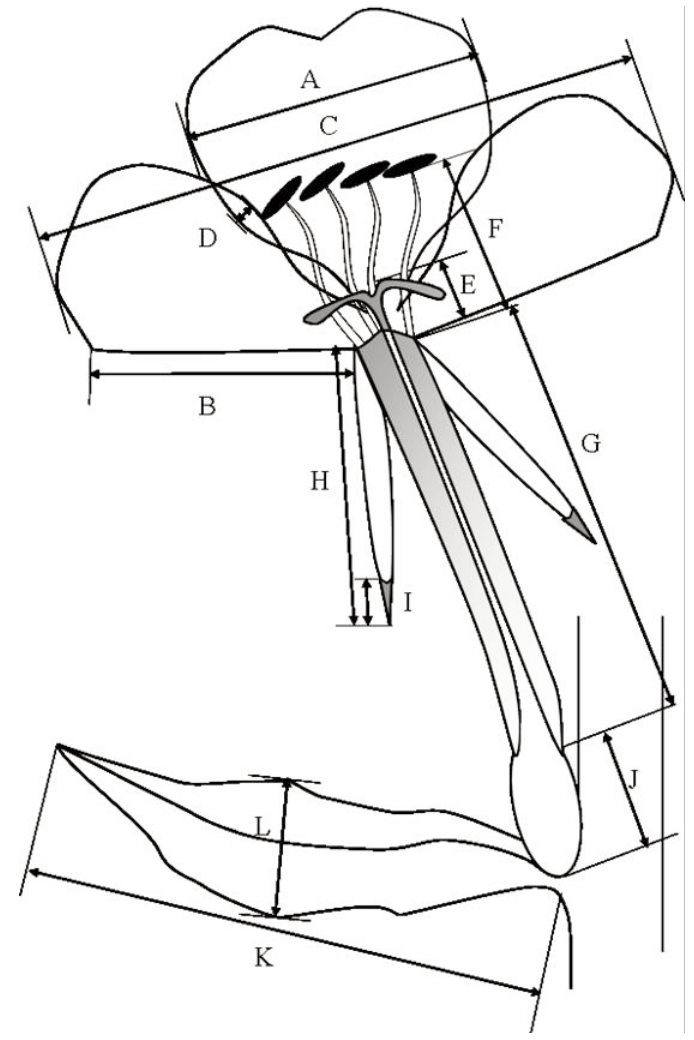

Fig. 2. Illustration of measurements taken. $\mathrm{A}=$ petal width, $\mathrm{B}=$ petal length, $\mathrm{C}=$ flower diameter, $\mathrm{D}=$ petal overlap, $\mathrm{E}=$ stigma height, $\mathrm{F}=$ filament length, $\mathrm{G}=$ corolla tube length, $\mathrm{H}=$ sepal length, $\mathrm{I}=$ sepal tip length, $\mathrm{J}=$ ovary length, $\mathrm{K}=$ bract length, $\mathrm{L}=$ bract width.

from all 4 petals on a flower), mean petal width, mean petal overlap, stigma height, filament length (for a single randomly chosen stamen per flower), corolla tube length, sepal length, free sepal tip length, ovary length, subtending bract length and width, and plant height (Fig. 2). All but petal width and length are independent of those used by previous botanists (Gisler and Meinke 1997, Imper 1997) in populationlevel identifications in the field. All measurements, except plant height, were taken with digital or dial calipers to the nearest $0.1 \mathrm{~mm}$. Plants were measured from 10 June to 3 August 2000.

\section{Statistical Methods}

To determine each individual's and population's position along a morphological continuum between putatively pure $O$. wolfii and pure O. glazioviana populations (i.e., end members), 

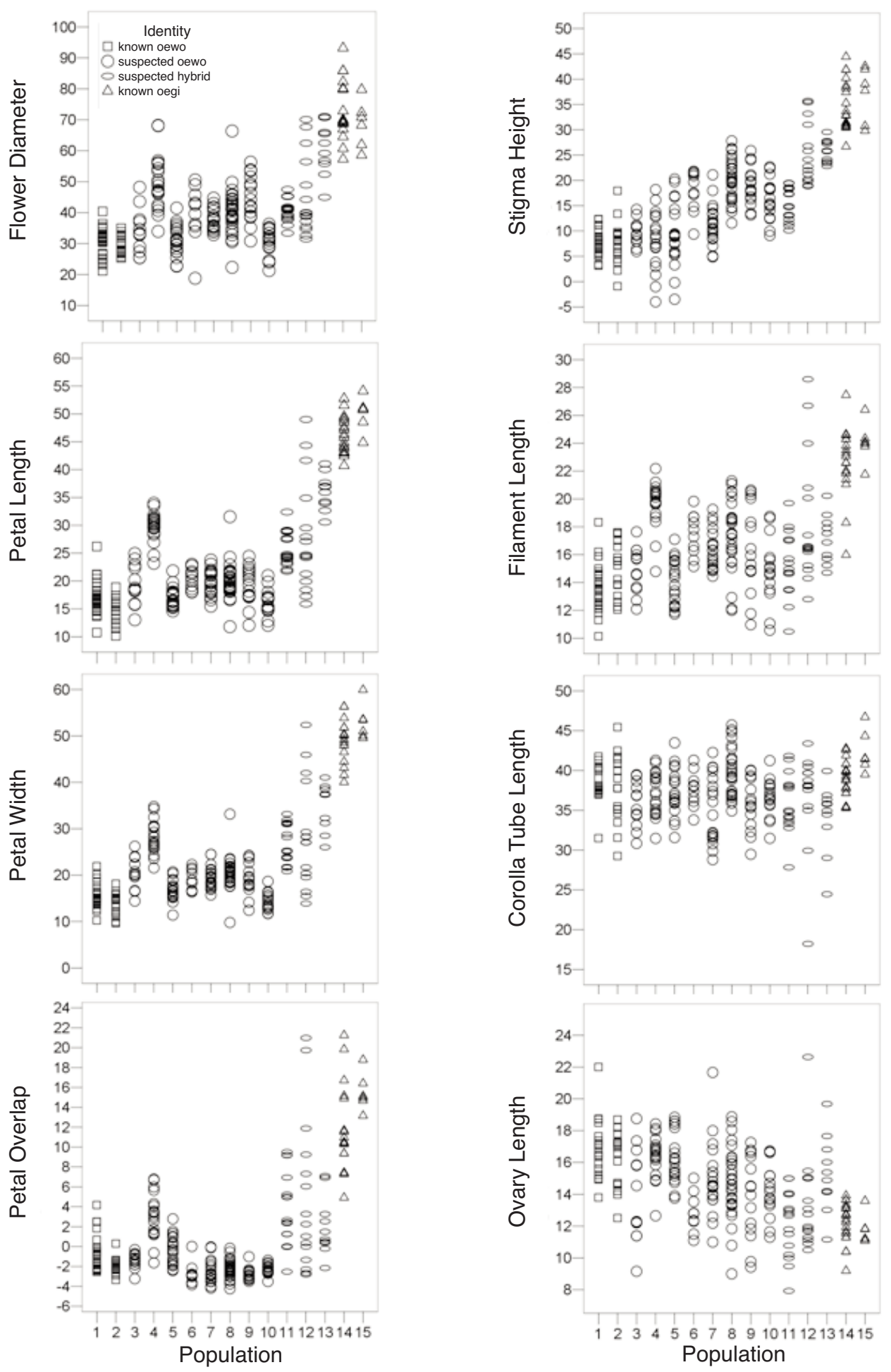

Fig. 3. Morphometric comparisons of 12 reproductive and vegetative traits among Oenothera types. Populations 1 and 2 are known pure $O$. wolfii, populations 3-10 are suspected $O$. wolfii, populations 11-13 are suspected hybrid populations, and populations 14 and 15 are pure O. glazioviana. All values are in millimeters, except plant height, which is in centimeters. 

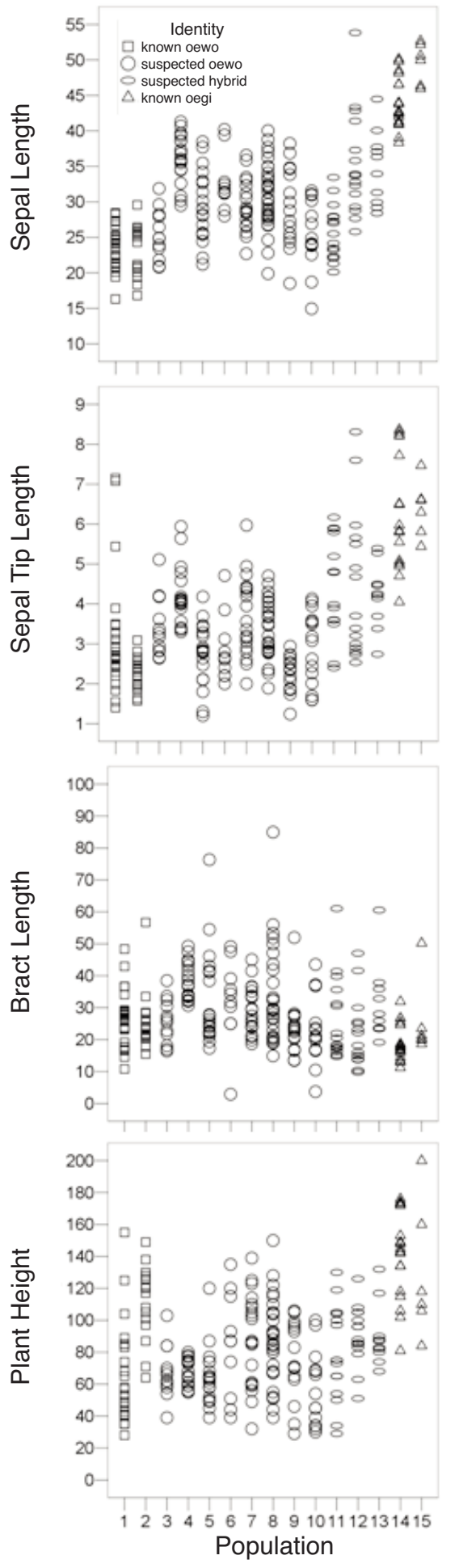

Fig. 3. Continued. we developed an index combining the morphological traits that most reliably distinguish the end members. This approach is commonly used to contrast biological communities from different environments (e.g., clean vs. polluted waters; Karr et al. 1986), and the method logically extends to other forms of multivariate data (i.e., multiple traits measured from individuals). We identified those traits that offer the greatest discrimination between the end-members (i.e., traits with less than $10 \%$ of individuals overlapping). When we considered traits to be developmentally linked (e.g., petal length and petal width), we used only 1 of the traits. For each individual in the end-member populations, we combined the discriminating traits (petal length, filament length, stigma height, sepal length, and ovary length) into a composite morphological index score by converting each trait's raw value into a percentile of the observed range (i.e., the smallest trait value $=0$ and the largest trait value $=100$ ) and then averaging the percentile scores of the discriminating traits. Oenothera wolfii was smaller for all traits except ovary length; we converted ovary length to [100 - ovary length] for all individuals so that smaller values across traits coincided with $O$. wolfii. We then converted raw trait values into composite morphological scores for all remaining populations. The distribution of index scores for each population was compared graphically and statistically (Student-Newman-Keuls test of homogeneous groups) to the end members.

We used principal components analysis to assess the clustering of Oenothera individuals in multivariate space, and discriminant function analysis was used to test for differences among suspected hybrid, suspected O. wolfii, and both pure parental populations. Discriminant function analysis also measured the degree of success of the classification of an individual to its population and presumed identity $(O$. wolfii, hybrid, or $O$. glazioviana), by producing an output of counts in which individuals within each population are correctly and incorrectly classified. To meet normality/covariance assumptions, we square-root or log transformed 3 variables; all other variables met the model assumptions. We used a stepwise variable selection model in SPSS Base 8.0 that adds variables step by step and does not add variables that do not help in discriminating populations (these variables tend to be linear functions of other variables). 


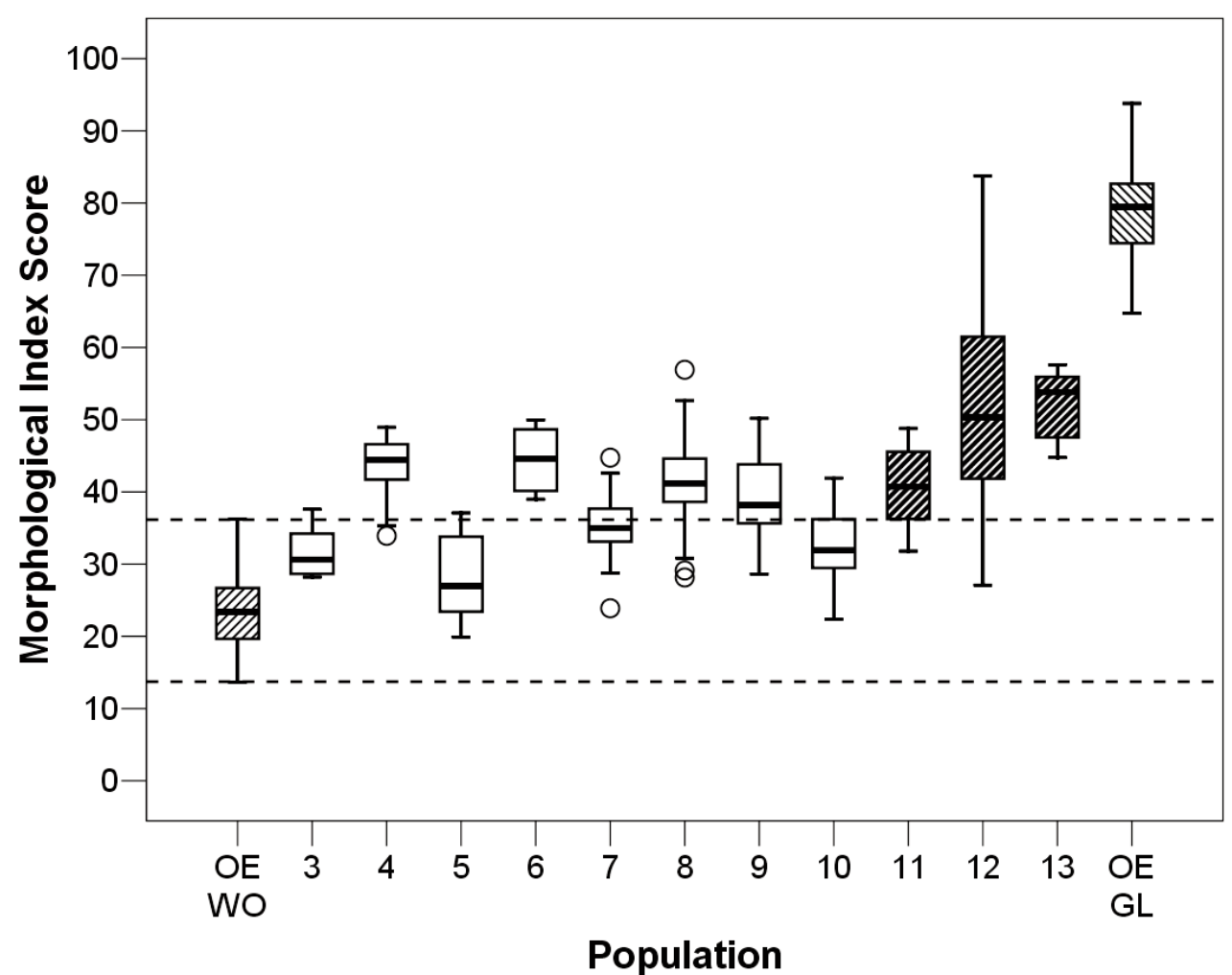

Fig. 4. Box and whisker plots of composite morphological index scores (see methods) for pure O. wolfii (OEWO, white), pure O. glazioviana (OEGL, dark gray), suspected O. wolfii (light gray), and hybrid populations (hatched). The numbers below indicate population identity. Populations that are of the same homogeneous subset (Student-NewmanKuels) share the same letter. For reference, the dashed lines indicate maximum and minimum composite index scores for known pure O. wolfii.

\section{RESULTS}

\section{Univariate Comparison}

Individuals from the 2 northern pure $O$. wolfii populations did not overlap with $O$. glazioviana plants in flower diameter, petal length, petal width, petal overlap, stigma height, and sepal length; and only $2 O$. wolfii individuals overlapped with $O$. glazioviana in ovary length (Table 1, Fig. 3). Two O. glazioviana individuals with unusually short filaments overlapped in length with $O$. wolfii. Corolla tube length, sepal tip length, bract length, bract width, and plant height broadly overlapped between the 2 pure groups. Oenothera wolfii was smaller for all traits except ovary length. Variation in trait values tended to be less for both pure $O$. wolfii populations and $O$. glazioviana populations relative to the suspected hybrids and suspected O. wolfii populations (Fig. 3).
Traits of $O$. wolfii individuals from populations with uncertain genetic backgrounds (i.e., "suspected O. wolfii") were variable and ranged between those of pure $O$. wolfii populations and those of suspected hybrids. Three traits showed a modest clinal relationship to latitude. For the pure and suspected O. wolfii individuals combined, stigma height was negatively correlated to latitude (linear regression, $R^{2}=$ $0.381, P<0.001$ ), and tube length and ovary length were weakly, but significantly positively correlated with latitude $\left(R^{2}=0.046, P=0.004\right.$, $R^{2}=0.96, P<0.001$, tube length and ovary length, respectively).

Individuals from 1 putative hybrid population (population 12) included a mixture of plants ranging from those appearing as pure $O$. wolfii to pure $O$. glazioviana and including intermediate individuals (Figs. 3, 4). The other 2 putative hybrid populations were much more uniform in morphology. Population 13 was composed 


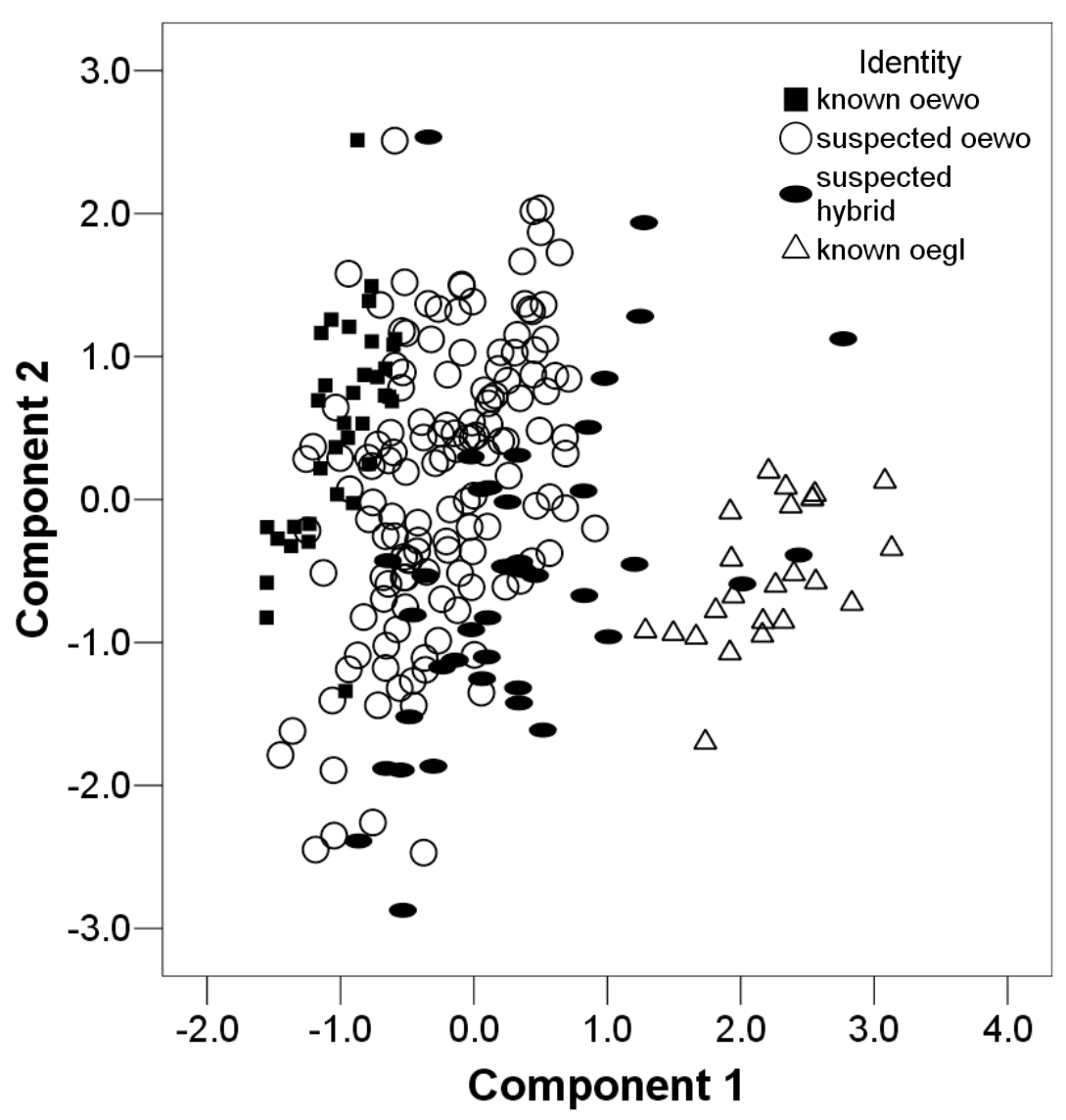

Fig. 5. Principal components scores for known pure O. wolfii (squares), suspected O. wolfii (circles), suspected hybrids (ellipses), and known pure O. glazioviana (triangles). Proximity of symbols is a direct measure of morphological similarity.

entirely of intermediate individuals with no overlap with the parental species in composite morphology, whereas population 11 had a minority of individuals that overlapped with pure O. wolfii (Figs. 3, 4).

\section{Multivariate Analysis}

Multivariate means (centroids) of the 4 Oenothera groups differed significantly $(P<0.001)$ from one another in the discriminant analysis and displayed minimal overlap in multivariate space (Fig. 5). The discriminant analysis correctly classified $100 \%$ of known pure O. wolfii and O. glazioviana. Two of 138 individuals (1.4\%) from suspected O. wolfii populations were classified as hybrids. Of the 3 hybrid populations, $20 \%$ of the individuals were predicted to belong to $O$. wolfii and $7.5 \%$ to $O$. glazioviana.

\section{Population-level Characterization}

The composite morphological index for pure species groups, suspected O. wolfii, and suspected hybrid populations is shown in Figure 4 . Although the 2 pure groups were clearly very different from each other, there was broad overlap among populations in the suspected $O$. wolfii and hybrid groups, making the identification of "pure" O. wolfii populations dubious. Populations 3 and 5 did not overlap significantly with the suspected hybrids and are clearly morphologically allied with the known pure O. wolfii, but the morphology of the remaining 6 suspected $O$. wolfii populations bled into those of the suspected hybrids. Populations $4,6,8$, and 9 , in particular, were not distinguishable from putative hybrid populations in this analysis (Fig. 4; 1-way ANOVA, $F_{12,241}$ $=102.6, P<0.001$, Student-Newman-Kuels 
post hoc homogeneous subsets). No individuals from population 6 and only roughly $15 \%$ of individuals from populations 4 and 8 overlapped in composite morphology with known pure $O$. wolfii individuals.

\section{Discussion}

\section{Evidence of Hybridization}

Our study demonstrates a wide and continuous range of morphological variation in Oenothera populations along beach and adjacent habitats in northern California and southern Oregon, consistent with the hypothesis of widespread hybridization between the rare $O$. wolfii and invasive $O$. glazioviana. Previously identified and presumably pure northern populations of O. wolfii (see Gisler and Meinke 1997, Imper 1997) were smaller in almost all 13 characters measured. A number of floral traits were useful in distinguishing the 2 parental species. Flower diameter, petal length and petal width, stigma height, and sepal length measurements did not overlap between the pure O. wolfii populations and O. glazioviana. Ovary length was also different between the 2 species despite a few $O$. wolfii plants with abnormally small ovaries. Sepal pubescence was not used in the analysis, but it appeared to be a strong character for separating $O$. wolfii (which is moderately villous) from O. glazioviana (which is weakly villous). Our measurements from pure $O$. wolfii populations were very similar to the minimum and maximum values reported for the species in the monograph of the subsection (Dietrich et al. 1997), but numerous individuals from suspected $O$. wolfii populations had petal and sepal traits that exceeded published values. Plants collected from hybrid populations had sepal pubescence that was not easily distinguished from pure $O$. wolfii, however. The ability to assign any single individual to a particular Oenothera group is questionable due to the levels of phenotypic plasticity in the parental taxa (see Gibbs 1968, Birch and Vogt 1970, Albert et al. 1997); the best approach is to measure multiple characteristics from a number of randomly selected individuals from a given population.

\section{Oenothera wolfii Populations}

All populations that had previously been assessed as $O$. wolfii by other researchers did not possess any $O$. glazioviana trait values, but many overlapped considerably with putative hybrid populations, despite the ability of the discriminant analysis to classify most suspected $O$. wolfii individuals according to their a priori group membership. Population 3, population 5 , and population 10 , the most southerly population, appeared to approach the morphology of the 2 pure $O$. wolfii populations from near Port Orford, Oregon. These populations are found on natural upper beach habitats with a significant buffer to anthropogenically disturbed habitats. All of these populations are believed to be free from introgression with $O$. glazioviana.

The remaining 5 O. wolfii populations, however, were composed of individuals intermediate between pure $O$. wolfii and O. glazioviana, some of which were classified as hybrids in the discriminant analysis. These populations (4, 6-9) were from more disturbed roadsides, quarries, or anthropogenically disturbed beaches. In particular, plants from population 4 were relatively uniform, with large flowers, some petal overlap (not classic $O$. wolfii traits), yet with a very short stigma height (a classic $O$. wolfii trait). This population exists on an old quarry site. Because of the less natural habitat and mix of morphological traits, it is possible that this is an older hybrid population that has drifted in morphology and become fixed for these traits. Alternatively, the population could have been founded by few hybrid propagules. It is also possible that environmental or environmentby-gene interactions are responsible for the unique morphology of this population.

The suspected $O$. wolfii populations of the Pistol River, Crescent City, and Wilson Creek populations (populations 6,8 , and 9 , respectively) had only a minority of individuals that look like $O$. wolfii from the northern pure populations. Most individuals had larger corollas, longer filaments, and shorter ovaries, thus approaching the morphology of individuals from suspected hybrid populations. It is most likely that these populations have incorporated some level of $O$. glazioviana genes; the Crescent City population, in particular, is only $100 \mathrm{~m}$ from clearly hybrid and O. glazioviana populations. An alternative explanation for the similarity of these populations and the suspected hybrid populations is that the identification of hybrid populations by previous researchers was incorrect, and that these are in fact $O$. wolfii. This seems implausible, but a 
molecular analysis of the chloroplast and nuclear genomes would assist greatly in identification of hybrids and offer insights into the links with morphology.

\section{Hybrid Populations}

Two of the 3 putative hybrid populations were morphologically quite similar to each other and displayed little variability. These populations were intermediate between the parental species, although most of the individuals from 1 population (population 11) were more similar to $O$. wolfii. These intermediate values indicate that the morphological traits measured were likely the result of additive genes (Albert et al. 1997), coupled with the permanent translocation heterozygous genetic system, which tends to result in low withinpopulation variability (Holsinger and Ellstrand 1984).

One hybrid population (population 12) was extremely morphologically variable, however. Some plants looked like O. glazioviana, some plants like $O$. wolfii, and many were intermediate. This wide range of expressed traits could be the result of independent segregation in a recently founded hybrid population (without consistent integration of the parental taxa's genomes in the permanent translocation hybrid linkage groups). However, this population appears to be an active zone of introgression. Large morphological variation, ranging from that found in both parental species through morphological intermediates, normally represents multigenerational crosses between parental species (Anderson 1949, Grant 1981, Albert et al. 1997); however, Rieseberg (1995) and Gisler (2003) explain that F1 hybrids often represent a mosaic of intermediate, parental, and extreme characters. This population is near an $O$. wolfii population along the upper beach. It is also close to a number of small populations of $O$. glazioviana. This hybrid population poses a very immediate threat to the genetic integrity of the adjacent Crescent City O. wolfii population, which may already be compromised.

It should be noted that morphological evidence used in studies of hybridization and introgression (see Rieseberg and Wendel 1993 for a review) does not allow the elimination of alternative explanations of morphological intermediacy. Genetic factors such as dominance, pleiotropy, and epistasis can alter the correspondence between genotype and morpholog- ical phenotype (Gallez and Gottleib 1982, Albert et al. 1997, Hardig et al. 2000). However, most morphological studies that have suggested introgression have been supported by re-examination using molecular techniques (with a few exceptions; Rieseberg and Wendel 1993, Rieseberg and Carney 1998). The addition of molecular methods would be useful in testing the morphological results in these Oenothera groups.

\section{Permament Translocation Heterozygosis}

These data show that discrete populationlevel morphotypes expected for permanent translocation heterozygote populations, which are sheltered from recombination, are not present for these populations. Population 4, however, seemed to be fixed for unique trait combinations. Strong environmental effects may mask discrete variation, and the apparent clinal variation in stigma height, tube length, and ovary length across populations suggests that environmental variation may be a significant factor. However, this variation may also have a genetic component, and it may reflect a greater frequency of $O$. glazioviana genes in southern populations. Lack of discrete variation is also possible if multiple genotypes are present in populations, which is believed to occur only rarely in these permanent translocation taxa (see Levin et al. 1972). However, the probability of multiple genotypes in populations with this genomic condition obviously increases under conditions of introgression, and the high within-population variation, compared with among-population variation, in this system suggests significant genetic exchange.

\section{Hybridization and Habitat}

Coastal Oregon and California land-use patterns contrast sharply, and the difference is reflected in the observed patterns in hybridization between the rare and introduced Oenothera species. The entire coastal strand is publicly owned and natural resources are protected in Oregon (1967 Oregon Beach Bill), while much of the California coast is privately owned and development commonly extends to the upper beaches, where $O$. wolfii occurs. Initial hybridization appears to have taken place where gardens of $O$. glazioviana abutted $O$. wolfii populations in northern California. We observed cultivated $O$. glazioviana growing approximately $100 \mathrm{~m}$ from O. wolfii in Crescent City, 
California. Nearly all populations of $O$. wolfii we visited in California were adjacent to roads or heavily used beaches and were clearly anthropogenically disturbed. Most of the Oregon populations are restricted to remote coastal sites with few nonnative species and minimal anthropogenic impacts.

Hybrid populations are exploiting a novel habitat type that also promotes its movement. The hybrids are occupying weakly vegetated road edges of imported fill in northern California. These populations can be composed of thousands of individuals, spread along many kilometers of major transportation corridors, and are moving northward into Oregon. Because many of the Oregon populations of $O$. wolfii are adjacent to the same road corridor that is heavily populated with hybrids in California, their future is dubious. The shift of hybrids to a novel habitat that happens to act as a vector for their spread is a serious threat to the remaining pure $O$. wolfii populations. Roads, in general, are noted as particularly troublesome habitats that tend to promote the establishment and dispersal of many invasive species (Christen and Matlack 2006).

\section{ACKNOWLEDGMENTS}

The authors gratefully acknowledge the technical and financial support of the U.S. Fish and Wildlife Service. Thanks go to Steven Gisler, Amber Wierck, Karen Brimacombe, Amy Love, Karen Rohland, Rhiannon Thomas, Jeremy Welty, and Daniel Rinella for their ideas and diligent labor in the field. Two anonymous reviewers gave detailed and helpful comments on an earlier version of this manuscript. Additional thanks go to Dave Imper who supplied us with population locality, demographic information, and species information.

\section{Literature Cited}

AввоTт, R.J., AND A.J. Lowe. 2004. Origins, establishment and evolution of new polyploidy species: Senecio cambrensis and S. eboracensis in the British Isles. Biological Journal of the Linnean Society 82:467-474.

Albert, M.E., C.M. D’Antonio, and K.A. Schierenbeck. 1997. Hybridization and introgression in Carpobrotus spp. (Aizoaceae) in California. I. Morphological evidence. American Journal of Botany 84:896-904.

ANDERSON, E. 1949. Introgressive hybridization. John Wiley \& Sons, Inc., New York.

BIRCH, L.C., AND W. VoGT. 1970. Plasticity of taxonomic characters of the Queensland fruit flies Dacus tryoni and Dacus neohumeralis (Tephritidae). Evolution 24: 320-343.

Brochmann, C. 1984. Hybridization and distribution of Argyranthemum coronopifolium (Asteraceae-Anthemideae) in the Canary Islands. Nordic Journal of Botany 4:729-736.

Chiu, W.L., and B.B. SEars. 1993. Plastome-genome interactions affect plastid transmission in Oenothera. Genetics 133:989-997.

Christen, D., and G. Matlack. 2006. The role of roads in plant invasions: a demographic approach. Conservation Biology 20:385-391.

Cleland, R.E. 1972. Oenothera, cytogenics and evolution. Academic Press, London.

Daehler, C.C., AND D.R. Strong. 1997. Hybridization between introduced smooth cordgrass (Spartina alterniflora: Poaceae) and native California cordgrass (S. foliosa) in San Francisco Bay, California, USA. American Journal of Botany 84:607-611.

Dietrich, W., W.L. Wagner, and P.H. Raven. 1997. Systematics of Oenothera section Oenothera subsection Oenothera (Onagraceae). Systematic Botany Monographs 50:1-234.

ElLstrand, N.C. 1992. Gene flow by pollen: implications for plant conservation genetics. Oikos 63:77-86.

ElLstrand, N.C., AND D.R. Elam. 1993. Population genetic consequences of small population size: implications for plant conservation. Annual Review of Ecology and Systematics 24:217-242.

Ellstrand, N.C., And K.A. Schierenbeck. 2000. Hybridization as a stimulus for the evolution of invasiveness in plants? Proceedings of the National Academy of Science 97:7043-7050.

Freas, K.E., AND D.D. Murphy. 1988. Taxomony and the conservation of the critically endangered Bakersfield saltbush, Atriplex tularensis. Biological Conservation 46:317-324.

GaLLEZ, G.P., AND L. GOTTLEIB. 1982. Genetic evidence for the hybrid origin of the diploid plant Stephanomeria diegensis. Evolution 36:1158-1167.

GiBBs, G.W. 1968. The frequency of interbreeding between two sibling species of Dacus (Diptera) in wild populations. Evolution 22:667-683.

GISLER, S.D. 2003. Reproductive isolation and interspecific hybridization in the threatened species Sidalcea nelsoniana. Master's thesis, Oregon State University, Corvallis.

Gisler, S.D., AND R.J. Meinke. 1997. Status report for Oenothera wolfii (Munz) Raven, Dietrich \& Stubbe. U.S. Fish and Wildlife Report, Portland, OR.

Grant, V. 1981. Plant speciation. Columbia University Press, New York.

Hardig, T.M., S.J. Brunsfeld, R.S. Fritz, M. Morgan, AND C.M. ORIans. 2000. Morphological and molecular evidence for hybridization and introgression in a willow (Salix) hybrid zone. Molecular Ecology 9:9-24.

Heiser, C.B. 1965. Sunflowers, weeds, and cultivated plants. Pages 375-386 in H. Baker and G. Stebbins, editors, The genetics of colonizing species. Academic Press, New York.

Holsinger, K.E., AND N.C. Ellstrand. 1984. The evolution and ecology of permanent translocation heterozygotes. American Naturalist 124:48-71.

Imper, D.K. 1997. Ecology and conservation of Wolf's evening primrose in northwestern California. Pages 34-40 in T.N. Kaye, A. Liston, R.M. Love, D.L. Luoma, R.J. Meinke, and M.V. Wilson, editors, 
Conservation and management of native plants and fungi. Native Plant Society of Oregon, Corvallis.

Karr, J.R., K.D. Fausch, P.L. Angermeier, P.R. Yant, and I.J. Schlosser. 1986. Assessing biological integrity in running waters: a method and its rationale. Illinois Natural History Survey Special Publication 5: $1-28$.

Levin, D.A., G.P. Howland, and E. Steiner. 1972. Protein polymorphism and genetic heterozygosity in a population of the permanent translocation heterozygote, Oenothera biennis. Proceedings of the National Academy of Science 69:1475-1477.

Levin, D.A., J. Francisco-Ortega, and R.K. Jansen. 1996. Hybridization and the extinction of rare plant species. Conservation Biology 10:10-16.

Liston, A., L.H. Rieseberg, and O. Mistretta. 1990. Ribosomal evidence for hybridization between island endemic species of Lotus. Biochemical Systematics and Ecology 18:239-244.

Malik, S.K., R. Chaudhury, O.P. Dhariwal, and R.K. KALIA. 2006. Collection and characterization of Citrus indica Tanaka and C. macroptera Montr.: wild endangered species of northeastern India. Genetic Resources and Crop Evolution 7:1485-1493.

McGranahan, G.H., J. Hansen, and D.V. Shaw. 1988. Inter- and intraspecific variation in California black walnuts. Journal of the American Society of Horticultural Science 113:760-765.

Prentis, P.J., E.M. White, I.J. Radford, A.J. Lowe, and A.R. Clarke. 2007. Can hybridization cause local extinction: a case for demographic swamping of the Australian native Senecio pinnatifolius by the invasive Senecio madagascariensis? New Phytologist [onlineearly articles]. doi:10.1111/j.1469-8137.2007.02217.x

Raven, P.H. 1979. A survey of reproductive biology in Onagraceae. New Zealand Journal of Botany 17:575593.

Raven, P.H., W. Dietrich, and W. Stubbe. 1979. An outline of the systematics of Oenothera subsection Euoenothera (Onagraceae). Systematic Botany 4:242-252.

Rhymer, J.M., AND D.S. SimberLoff. 1996. Extinction by hybridization and introgression. Annual Review of Ecology and Systematics 27:83-109.

RIESEBERG, L.H. 1991. Hybridization in rare plants: insights from case studies in Cercocarpus and Helianthus. Pages 171-181 in D.A. Falk and K.E. Holsinger, edi- tors, Genetics and conservation of rare plants. Oxford University Press, London.

1995. The role of hybridization in evolution: old wine in new skins. American Journal of Botany 82: 944-953.

Rieseberg, L.H., and S.E. Carney. 1998. Tansley review no. 102: plant hybridization. New Phytologist 140: 599-624.

Rieseberg, L.H., AND J. WENDEL. 1993. Introgression and its consequences in plants. Pages 70-109 in R. Harrison, editor, Hybrid zones and the evolutionary process. Oxford University Press, New York.

Rogers, C.E., T.E. Thompson, and G.J. Seiler. 1982. Sunflower species of the United States. National Sunflower Association, Bismark, ND.

SkinNeR, M.W., AND B.M. PAVLIK. 1994. Inventory of rare and endangered vascular plants of California. Special Publication No. 1, California Native Plant Society, Sacramento.

Stace, C.A. 1991. New flora of the British Isles. Columbia University, Cambridge.

Stubbe, W. 1964. The role of the plastome in the evolution of the genus Oenothera. Genetica 35:28-33.

Thompson, J.D. 1991. The biology of an invasive plant. BioScience 41:393-401.

Vilà, M., E. Weber, And C.M. D’Antonio. 2000. Conservation implications of invasion by plant hybridization. Biological Invasions 2:207-217.

WAGNER, W.L. 1993. Onagraceae (family description and key), Camissomia, Gaura, and Oenothera (Onagraceae). Pages 776-786, 798, 800-804 in J.C. Hickman, editor, The Jepson manual: higher plants of California. University of California Press, Berkley.

Wasmund, O., AND W. Stubbe. 1986. Cytogenic investigations on Oenothera wolfii (Onagraceae). Plant Systematics and Evolution 154:79-88.

Whitney, K.D., R.A. Randall, and L.H. Rieseberg. 2006. Adaptive introgression of herbivore resistance traits in the weedy sunflower Helianthus anuus. American Naturalist 167:794-807.

Wolf D.E., N. Takebayashi, and L.H. Rieseberg. 2001. Predictiong the risk of extinction through hybridization. Conservation Biology 4:1039-1053.

Received 14 December 2006 Accepted 13 December 2007 